\title{
Discrete-Time Nonlinear Control of VSC-HVDC System
}

\author{
TianTian Qian and ShiHong Miao \\ State Key Laboratory of Advanced Electromagnetic Engineering and Technology, \\ Huazhong University of Science and Technology, Wuhan 430074, China \\ Correspondence should be addressed to ShiHong Miao; shmiao@hust.edu.cn
}

Received 17 March 2015; Revised 19 May 2015; Accepted 28 May 2015

Academic Editor: Miguel A. F. Sanjuan

Copyright (C) 2015 T. Qian and S. Miao. This is an open access article distributed under the Creative Commons Attribution License, which permits unrestricted use, distribution, and reproduction in any medium, provided the original work is properly cited.

Because VSC-HVDC is a kind of strong nonlinear, coupling, and multi-input multioutput (MIMO) system, its control problem is always attracting much attention from scholars. And a lot of papers have done research on its control strategy in the continuous-time domain. But the control system is implemented through the computer discrete sampling in practical engineering. It is necessary to study the mathematical model and control algorithm in the discrete-time domain. The discrete mathematical model based on output feedback linearization and discrete sliding mode control algorithm is proposed in this paper. And to ensure the effectiveness of the control system in the quasi sliding mode state, the fast output sampling method is used in the output feedback. The results from simulation experiment in MATLAB/SIMULINK prove that the proposed discrete control algorithm can make the VSC-HVDC system have good static, dynamic, and robust characteristics in discrete-time domain.

\section{Introduction}

Voltage source converter based high voltage direct current (VSC-HVDC) technology which uses advanced (insulated gate bipolar transistor) IGBT device and pulse width modulation (PWM) method overcomes the disadvantage of traditional HVDC. It can not only adjust the active and reactive power independently, but also supply power to passive network system. Therefore the VSC-HVDC technology has a broad application prospect in the fields of distributed generation, asynchronous AC network interconnection, remotearea power supply, and so forth [1-5].

Because VSC-HVDC is a multiple input multiple output, strong coupling nonlinear system, its control problem is always attracting much attention from the scholars. In chronological order, its research process can be classified into the following two phases.

(1) The steady state mathematical model and basic control strategy of VSC-HVDC system: [6] developed the steady state model and proposed control strategy which combined an inverse model controller with a PI controller. Reference [7] presented an equivalent continuous-time state space model of VSCHVDC in the synchronous $d-q$ reference frame and proposed a decoupled PI control strategy using the feed-forward compensation method. Reference [8] presented the elements of VSC-HVDC and proposed a feed-forward decoupled current control strategy. In this phase, the study is mainly based on the traditional PI controllers under the linear decoupling control strategy. The design method of this kind of control strategy is easy. And it shows good adjustment ability. But the parameters of PI controllers are fixed, and their adjustment ability is limited. When system suffers from large disturbance, they show weak robustness and dynamic characteristics. Some severe cases can lead to sustained oscillation of the system. Therefore some scholars started the second phase study.

(2) Optimizing and nonlinear control strategy of the VSC-HVDC system: [9] proposed an adaptive control design to improve dynamic performances of VSCHVDC systems. The adaptive controllers designed for nonlinear characteristics of VSC-HVDC systems, which were based on back stepping method, considered parameters uncertainties. Reference [10] presented a robust nonlinear controller for VSC-HVDC transmission link using input-output linearization 
and sliding mode control strategy. The feedback linearization was used to cancel nonlinearity and the sliding mode control offered invariant stability to modeling uncertainties. Reference [11] proposed the controller design based on Ho control methodologies to deal with the nonlinearities introduced by requirements to power flow and line voltage. Reference [12] addressed two different robust nonlinear control methodologies based on sliding mode control for the VSC-HVDC transmission system's performance enhancement and stability improvement. In this phase, the studies are based on the nonlinear control, robust control, and optimizing control of the VSC-HVDC system. The experimental results from research papers show these control strategies can improve static, dynamic, and robust performance of VSC-HVDC system.

However, the referred literatures are based on the continuoustime state. In practice, nowadays most controllers are implemented in discrete time. It is known that the realization of a controller using digital elements and complex programmable logic devices can achieve maximum reproducibility at minimum cost. So it is necessary to do research on the discrete model and control strategy. In [13], the discrete PI controllers of VSC-HVDC system were established. Reference [14] studied the discrete PI control algorithm of VSC-HVDC system which supplied power to the passive network.

But so far, the discrete-time mathematic model and control strategy based on nonlinear control methods are seldom studied by scholars. Through proper feedback linearization control strategy, complex nonlinear system synthesis problems can be transformed to linear system synthesis problems. As a kind of robust control method, sliding mode control is versatile to linear and nonlinear system. It is easy to be designed and carried out. Because of its complete robustness to the parameters change and external disturbances which meet the match condition, it gets extensive attention from scholars and engineers [15].

Therefore, the discrete mathematical model of the VSCHVDC system based on nonlinear feedback linearization and discrete sliding mode control algorithm are proposed in this paper. And the fast output sampling (FOS) technique is adopted in the output feedback, which ensures the stability of the closed loop system in the condition of quasi sliding mode control. The simulation results performed in MATLAB/SIMULINK show that the proposed discrete control strategy can make the VSC-HVDC system have good operation performance.

\section{The Mathematical Model of VSC-HVDC}

2.1. Continuous-Time State Space Model. The structure diagram of VSC-HVDC is shown in Figure 1. The more widely used continuous-time mathematical models based on the synchronous reference coordinates are employed in this paper, which are shown as (1) and (7).
2.1.1. Rectifier Side. Choose state variables $\mathbf{x}_{\mathbf{1 , 2}}=\left(\begin{array}{ll}i_{r d} & i_{r q}\end{array}\right)^{T}$, controlled variables $\mathbf{u}_{\mathbf{1 , 2}}=\left(\begin{array}{ll}U_{c r d} & U_{c r q}\end{array}\right)^{T}$, and output variables $\mathbf{y}_{\mathbf{1}, \mathbf{2}}=\left(\begin{array}{ll}i_{r d} & i_{r q}\end{array}\right)^{T}$. The mathematical model of the rectifier side is shown as

$$
\begin{aligned}
& \dot{x}_{1}=\frac{-R_{r}}{L_{r}} x_{1}+\omega_{r} x_{2}+\frac{U_{s r d}}{L_{r}}-\frac{1}{L_{r}} u_{1}, \\
& \dot{x}_{2}=\frac{-R_{r}}{L_{r}} x_{2}-\omega_{r} x_{1}+\frac{U_{s r q}}{L_{r}}-\frac{1}{L_{r}} u_{2}, \\
& y_{1}=x_{1}, \\
& y_{2}=x_{2},
\end{aligned}
$$

where $i_{r d}, i_{r q}$ and $U_{s r d}, U_{s r q}$ are the $d-q$ axis currents and voltages on the rectifier side, respectively. $U_{c r d}$ and $U_{c r q}$ are, respectively, the $d-q$ axis control inputs on the rectifier side. $R_{r}$ and $L_{r}$ are the corresponding equivalent resistance and the inductance on the rectifier side. $\omega_{r}$ is the AC system frequency on the rectifier side.

Here, the output variables on the rectifier side should be $\left(P_{r} Q_{r}\right)^{T} . P_{r}$ and $Q_{r}$ are, respectively, the output values of active and reactive power on the rectifier side. For convenience, define $U_{s r}$ as the line voltage effective value of the rectifier power supply. Define the $d$ axis in the synchronization reference frame coincidence with $a$ axis in the three-phase reference coordinate, so $U_{s r d}=U_{s r}, U_{s r q}=0$, $\left[\begin{array}{c}P_{r} \\ Q_{r}\end{array}\right]=\left[\begin{array}{cc}U_{s r d} & U_{s r q} \\ -U_{s r q} & U_{s r d}\end{array}\right]\left[\begin{array}{l}i_{r d} \\ i_{r q}\end{array}\right]=\left[\begin{array}{l}U_{s r} i_{r d} \\ U_{s r} i_{r q}\end{array}\right]$. Therefore the output variables can be chosen as $\mathbf{y}_{\mathbf{1 , 2}}=\left(\begin{array}{ll}i_{r d} & i_{r q}\end{array}\right)^{T}$.

Define

$$
\begin{aligned}
& f_{1}=\frac{-R_{r}}{L_{r}} x_{1}+\omega_{r} x_{2}+\frac{U_{s r d}}{L_{r}}, \\
& f_{2}=\frac{-R_{r}}{L_{r}} x_{2}-\omega_{r} x_{1}+\frac{U_{s r q}}{L_{r}}, \\
& \mathbf{f}_{r}=\left(f_{1}, f_{2}\right)^{T}, \\
& \mathbf{g}_{\mathbf{1}}=\left(-\frac{1}{L_{r}}, 0\right)^{T}, \\
& \mathbf{g}_{\mathbf{2}}=\left(0,-\frac{1}{L_{r}}\right)^{T} .
\end{aligned}
$$

Therefore (1) can be reorganized by

$$
\begin{aligned}
& \dot{\mathbf{x}}_{\mathbf{1 , 2}}=\mathbf{f}_{r}+\mathbf{g}_{1} u_{1}+\mathbf{g}_{2} u_{2}, \\
& \mathbf{y}_{\mathbf{1 , 2}}=\left(\begin{array}{l}
h_{1}(x) \\
h_{2}(x)
\end{array}\right)=\left(\begin{array}{l}
x_{1} \\
x_{2}
\end{array}\right) .
\end{aligned}
$$

Then, do exact feedback linearization on system equation (3). By calculation, the relative degree of $y_{1}$ is denoted by $\gamma_{1}=1$. The relative degree of $y_{2}$ is denoted by $\gamma_{2}=1$. Based on the feedback linearization theory [16], the exact feedback 


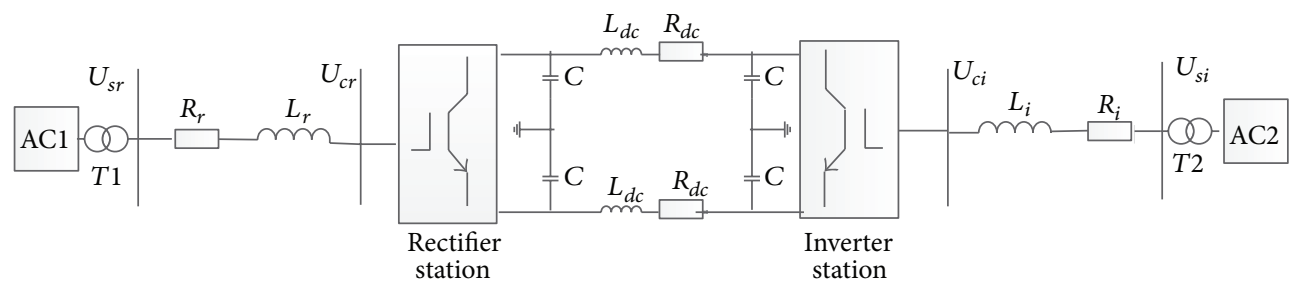

FIGURE 1: Structure diagram of VSC-HVDC system.

linearization state equations of the rectifier side are obtained as

$$
\begin{aligned}
\left(\begin{array}{l}
\dot{y}_{1} \\
\dot{y}_{2}
\end{array}\right)= & \left(\begin{array}{l}
\dot{x}_{1} \\
\dot{x}_{2}
\end{array}\right)=\left(\begin{array}{l}
v_{1} \\
v_{2}
\end{array}\right) \\
= & \left(\begin{array}{c}
L_{f_{r}}^{\gamma_{1}} h_{1} \\
L_{f_{r}}^{\gamma_{2}} h_{2}
\end{array}\right) \\
& +\left(\begin{array}{cc}
L_{g_{1}} L_{f_{r}}^{\gamma_{1}-1} h_{1} & L_{g_{2}} L_{f_{r}}^{\gamma_{1}-1} h_{1} \\
L_{g_{1}} L_{f_{r}}^{\gamma_{2}-1} h_{2} & L_{g_{2}} L_{f_{r}}^{\gamma_{2}-1} h_{2}
\end{array}\right)\left(\begin{array}{l}
u_{1} \\
u_{2}
\end{array}\right), \\
\left(\begin{array}{c}
\dot{x}_{1} \\
\dot{x}_{2}
\end{array}\right)= & \left(\begin{array}{l}
v_{1} \\
v_{2}
\end{array}\right)=\left(\begin{array}{ll}
\frac{-1}{f_{1}} & 0 \\
f_{2}
\end{array}\right)+\left(\begin{array}{cc}
L_{r} & -1 \\
0 & \frac{L_{r}}{L_{r}}
\end{array}\right)\left(\begin{array}{l}
u_{1} \\
u_{2}
\end{array}\right) .
\end{aligned}
$$

Because $\left|\begin{array}{cc}-1 / L_{r} & 0 \\ 0 & -1 / L_{r}\end{array}\right|=1 / L_{r}^{2} \neq 0,\left(\begin{array}{cc}-1 / L_{r} & 0 \\ 0 & -1 / L_{r}\end{array}\right)$ is nonsingular.

The controlled variables $u_{1}$ and $u_{2}$ can be denoted by virtual control variables $v_{1}$ and $v_{2}$ :

$$
\left(\begin{array}{l}
u_{1} \\
u_{2}
\end{array}\right)=\left(\begin{array}{l}
L_{r}\left(f_{1}-v_{1}\right) \\
L_{i}\left(f_{2}-v_{2}\right)
\end{array}\right) .
$$

To make it convenient for using FOS (fast output sampling) technique in Section 3.1 [17], substitute (5) into (3); then the system equation of rectifier side can be denoted by

$$
\begin{aligned}
& \dot{x}_{1}=v_{1}, \\
& \dot{x}_{2}=v_{2}, \\
& y_{1}=x_{1}, \\
& y_{2}=x_{2} .
\end{aligned}
$$

2.1.2. Inverter Side. Choose state variables $\mathbf{x}_{\mathbf{3 , 4 , 5}}=$ $\left(\begin{array}{lll}i_{i d} & i_{i q} & U_{d c 2}\end{array}\right)^{T}$, controlled variables $\mathbf{u}_{\mathbf{3}, \mathbf{4}}=\left(\begin{array}{ll}U_{c i d} & U_{c i q}\end{array}\right)^{T}$, and output variables $\mathbf{y}_{\mathbf{3}, \mathbf{4}}=\left(\begin{array}{ll}U_{d c 2} & i_{i q}\end{array}\right)^{T}$. The mathematical model of inverter side is shown as

$$
\begin{aligned}
& \dot{x}_{3}=\frac{-R_{i}}{L_{i}} x_{3}+\omega_{i} x_{4}+\frac{U_{s i d}}{L_{i}}-\frac{1}{L_{i}} u_{3}, \\
& \dot{x}_{4}=\frac{-R_{i}}{L_{i}} x_{4}-\omega_{i} x_{3}+\frac{U_{s i q}}{L_{i}}-\frac{1}{L_{i}} u_{4},
\end{aligned}
$$

$$
\begin{aligned}
& \dot{x}_{5}=\frac{U_{s i d} x_{3}+U_{s i q} x_{4}-R_{i}\left(x_{3}{ }^{2}+x_{4}{ }^{2}\right)}{C x_{5}}+\frac{U_{d c 1}-x_{5}}{C R_{d c}}, \\
& y_{3}=x_{5} \\
& y_{4}=x_{4}
\end{aligned}
$$

where $i_{i d}, i_{i q}$ and $U_{s i d}, U_{s i q}$ are the $d-q$ axis currents and voltages on the inverter side, respectively. $U_{c i d}$ and $U_{\text {ciq }}$ are, respectively, the control inputs on the inverter side. $R_{i}$ and $L_{i}$ are the corresponding equivalent resistance and the inductance on the inverter side. $U_{d c 1}$ and $U_{d c 2}$ are, respectively, the DC voltages on the rectifier side and inverter side. $C$ and $R_{d c}$ are, respectively, the converter station capacitance and DC line resistance. $\omega_{i}$ is the $\mathrm{AC}$ system frequency on the inverter side.

Here, the output variables on the inverter side should be $\left(U_{d c 2} Q_{i}\right) . Q_{i}$ is the output value of reactive power on the inverter side. For convenience, define $U_{s i}$ as the line voltage effective value of the inverter side power source. Define the $d$ axis in the synchronization reference frame that coincides with $a$ axis in the three-phase reference coordinate, so $U_{\text {sid }}=$ $U_{s i}, U_{\text {siq }}=0$, and $Q_{i}=-U_{s i q} i_{i d}+U_{s i d} i_{i q}=U_{s i} i_{i q}$. Therefore the output variables can be chosen as $\mathbf{y}_{\mathbf{3 , 4}}=\left(\begin{array}{ll}U_{d c 2} & i_{i q}\end{array}\right)^{T}$.

Define

$$
\begin{aligned}
& f_{3}=\frac{-R_{i}}{L_{i}} x_{3}+\omega_{i} x_{4}+\frac{U_{s i d}}{L_{i}}, \\
& f_{4}=\frac{-R_{i}}{L_{i}} x_{4}-\omega_{i} x_{3}+\frac{U_{s i q}}{L_{i}}, \\
& f_{5}=\frac{U_{\text {sid }} x_{3}+U_{s i q} x_{4}-R_{i}\left(x_{3}^{2}+x_{4}^{2}\right)}{C x_{5}}+\frac{U_{d c 1}-x_{5}}{C R_{d c}}, \\
& \mathbf{f}_{i}=\left(f_{3}, f_{4}, f_{5}\right)^{T}, \\
& \mathbf{g}_{3}=\left(-\frac{1}{L_{i}}, 0,0\right)^{T}, \\
& \mathbf{g}_{4}=\left(0,-\frac{1}{L_{i}}, 0\right)^{T} .
\end{aligned}
$$


Therefore (7) can be reorganized by

$$
\begin{aligned}
\dot{\mathbf{x}}_{\mathbf{3}, \mathbf{4}, \mathbf{5}} & =\mathbf{f}_{i}+\mathbf{g}_{3} u_{3}+\mathbf{g}_{4} u_{4}, \\
\mathbf{y}_{3,4} & =\left(\begin{array}{l}
h_{3}(x) \\
h_{4}(x)
\end{array}\right)=\left(\begin{array}{l}
x_{5} \\
x_{4}
\end{array}\right) .
\end{aligned}
$$

Then, do exact feedback linearization on system (9). By calculation, the relative degree of $y_{3}$ is denoted by $\gamma_{3}=2$. The relative degree of $y_{4}$ is denoted by $\gamma_{4}=1$. Based upon the feedback linearization theory [16], the exact feedback linearization state equations of inverter side are obtained as

$$
\begin{aligned}
\left(\begin{array}{c}
\ddot{y}_{3} \\
\dot{y}_{4}
\end{array}\right)= & \left(\begin{array}{l}
\ddot{x}_{5} \\
\dot{x}_{4}
\end{array}\right)=\left(\begin{array}{c}
v_{3} \\
v_{4}
\end{array}\right) \\
= & \left(\begin{array}{c}
L_{f_{i}}^{\gamma_{3}} h_{3} \\
L_{f_{i}}^{\gamma_{4}} h_{4}
\end{array}\right) \\
& +\left(\begin{array}{cc}
L_{g_{3}} L_{f_{i}}^{\gamma_{3}-1} h_{3} & L_{g_{4}} L_{f_{i}}^{\gamma_{3}-1} h_{3} \\
L_{g_{3}} L_{f_{i}}^{\gamma_{4}-1} h_{4} & L_{g_{4}} L_{f_{i}}^{\gamma_{4}-1} h_{4}
\end{array}\right)\left(\begin{array}{l}
u_{3} \\
u_{4}
\end{array}\right), \\
\left(\begin{array}{c}
\ddot{x}_{5} \\
\dot{x}_{4}
\end{array}\right)= & \left(\begin{array}{c}
v_{3} \\
v_{4}
\end{array}\right) \\
= & \left(\begin{array}{c}
a_{1} f_{3}+a_{2} f_{4}+a_{3} f_{5} \\
f_{4}
\end{array}\right) \\
& +\left(\begin{array}{cc}
\frac{-a_{1}}{L_{i}} & \frac{-a_{2}}{L_{i}} \\
0 & \frac{-1}{L_{i}}
\end{array}\right)\left(\begin{array}{l}
u_{3} \\
u_{4}
\end{array}\right),
\end{aligned}
$$

where

$$
\begin{aligned}
& a_{1}=\frac{\partial f_{5}}{\partial x_{3}}=\frac{U_{s i d}-2 R_{i} x_{3}}{C x_{5}}, \\
& a_{2}=\frac{\partial f_{5}}{\partial x_{4}}=\frac{U_{s i q}-2 R_{i} x_{4}}{C x_{5}}, \\
& a_{3}=\frac{\partial f_{5}}{\partial x_{5}}=-\frac{U_{s i d} x_{3}+U_{s i q} x_{4}-R_{i}\left(x_{3}^{2}+x_{4}^{2}\right)}{C x_{5}^{2}}-\frac{1}{C R_{d c}} .
\end{aligned}
$$

Because $\left|\begin{array}{cc}-a_{1} / L_{i} & -a_{2} / L_{i} \\ 0 & -1 / L_{i}\end{array}\right|=a_{1} / L_{i}^{2} \neq 0,\left(\begin{array}{cc}-a_{1} / L_{i} & -a_{2} / L_{i} \\ 0 & -1 / L_{i}\end{array}\right)$ is nonsingular.

The controlled variables $u_{3}$ and $u_{4}$ can be denoted by virtual control variables $v_{3}$ and $v_{4}$ :

$$
\left(\begin{array}{l}
u_{3} \\
u_{4}
\end{array}\right)=\left(\begin{array}{c}
\left(a_{1} f_{1}+a_{3} f_{3}-v_{3}+a_{2} v_{4}\right) \cdot \frac{L_{i}}{a_{1}} \\
L_{i}\left(f_{4}-v_{4}\right)
\end{array}\right) .
$$

To make it convenient for using FOS (fast output sampling) technology in Section 3.1 [17], substitute $a_{1}, a_{2}, a_{3}$, and (12) into (7); then the system equation of inverter side can be denoted by

$$
\begin{aligned}
& \dot{x}_{3}=\left(\frac{a_{3}^{2}}{a_{1}}+\frac{a_{3}}{a_{1} C R_{d c}}\right) x_{5}+\frac{1}{a_{1}} v_{3}-\frac{a_{2}}{a_{1}} v_{4}, \\
& \dot{x}_{4}=v_{4}, \\
& \dot{x}_{5}=\left(-a_{3}-\frac{1}{C R_{d c}}\right) x_{5}, \\
& y_{3}=x_{5}, \\
& y_{4}=x_{4} .
\end{aligned}
$$

Here, $\dot{x}_{5}$ should be $\dot{x}_{5}=\left(-a_{3}-1 / C R_{d c}\right) x_{5}+\left(U_{d c 1}-x_{5}\right) / C R_{d c}$. Since, during normal operation, $U_{d c 1}$ is approximately equal to $x_{5}$, for convenient calculation, $\dot{x}_{5}$ is simplified into $\dot{x}_{5}=$ $\left(-a_{3}-1 / C R_{d c}\right) x_{5}$.

2.2. Discrete-Time State Space Model. Discretize the virtual control variables $v_{1}, v_{2}, v_{3}$, and $v_{4}$ with sampling time $\tau$ :

$$
\begin{aligned}
& \left(\begin{array}{l}
v_{1}(k) \\
v_{2}(k)
\end{array}\right)=\left(\begin{array}{c}
\frac{y_{1}(k+1)-y_{1}(k)}{\tau} \\
\frac{y_{2}(k+1)-y_{2}(k)}{\tau}
\end{array}\right) \\
& =\left(\begin{array}{c}
\frac{x_{1}(k+1)-x_{1}(k)}{\tau} \\
\frac{x_{2}(k+1)-x_{2}(k)}{\tau}
\end{array}\right) \\
& =\left(\begin{array}{l}
f_{1}(k) \\
f_{2}(k)
\end{array}\right)+\left(\begin{array}{cc}
\frac{-1}{L_{r}} & 0 \\
0 & \frac{-1}{L_{r}}
\end{array}\right)\left(\begin{array}{l}
u_{1}(k) \\
u_{2}(k)
\end{array}\right), \\
& \left(\begin{array}{c}
v_{3}(k) \\
v_{4}(k)
\end{array}\right)=\left(\begin{array}{c}
\frac{y_{3}(k+2)-2 y_{3}(k+1)+y_{3}(k)}{\tau^{2}} \\
\frac{y_{4}(k+1)-y_{4}(k)}{\tau}
\end{array}\right) \\
& =\left(\begin{array}{c}
\frac{x_{5}(k+2)-2 x_{5}(k+1)+x_{5}(k)}{\tau^{2}} \\
\frac{x_{4}(k+1)-x_{4}(k)}{\tau}
\end{array}\right) \\
& =\left(\begin{array}{c}
a_{1} f_{3}(k)+a_{2} f_{4}(k)+a_{3} f_{5}(k) \\
f_{4}(k)
\end{array}\right) \\
& +\left(\begin{array}{cc}
\frac{-a_{1}}{L_{i}} & \frac{-a_{2}}{L_{i}} \\
0 & \frac{-1}{L_{i}}
\end{array}\right)\left(\begin{array}{l}
u_{3}(k) \\
u_{4}(k)
\end{array}\right)
\end{aligned}
$$


Discretize system equations (6), (13) with sampling time $\tau$, shown as

$$
\begin{aligned}
x_{1}(k+1)= & x_{1}(k)+\tau v_{1}(k), \\
x_{2}(k+1)= & x_{2}(k)+\tau v_{2}(k), \\
y_{1}(k)= & x_{1}(k), \\
y_{2}(k)= & x_{2}(k), \\
x_{3}(k+1)= & x_{3}(k)+\left(\frac{\tau a_{3}^{2}}{a_{1}}+\frac{\tau a_{3}}{a_{1} C R_{d c}}\right) x_{5}(k) \\
& +\frac{\tau}{a_{1}} v_{3}(k)-\frac{\tau a_{2}}{a_{1}} v_{4}(k), \\
x_{4}(k+1)= & x_{4}(k)+\tau v_{4}(k), \\
x_{5}(k+1)= & \left(1-\tau a_{3}-\frac{\tau}{C R_{d c}}\right) x_{5}(k), \\
y_{3}(k)= & x_{5}(k), \\
y_{4}(k)= & x_{4}(k) .
\end{aligned}
$$

Rearrange (16), and then get

$$
\begin{aligned}
& \mathbf{x}_{1,2}(\mathbf{k}+\mathbf{1})=\mathbf{A}_{\mathbf{r} \tau} \mathbf{x}_{1,2}(\mathbf{k})+\mathbf{B}_{\mathbf{r} \tau} \boldsymbol{v}_{1,2}(\mathbf{k}), \\
& \mathbf{y}_{1,2}(\mathbf{k})=\mathrm{C}_{\mathbf{r}} \mathbf{x}_{1,2}(\mathbf{k}), \\
& \mathbf{x}_{3,4,5}(\mathbf{k}+\mathbf{1})=\mathrm{A}_{\mathrm{i} \tau} \mathbf{x}_{3,4,5}(\mathbf{k})+\mathrm{B}_{\mathrm{i} \tau} \boldsymbol{v}_{3, \mathbf{4}}(\mathbf{k}), \\
& \mathbf{y}_{3,4}(\mathbf{k})=\mathbf{C}_{\mathbf{i}} \mathbf{x}_{3,4,5}(\mathbf{k}),
\end{aligned}
$$

where

$$
\begin{aligned}
& \mathbf{A}_{\mathbf{r} \tau}=\left(\begin{array}{ll}
1 & 0 \\
0 & 1
\end{array}\right) \\
& \mathbf{B}_{\mathbf{r} \tau}=\left(\begin{array}{ll}
\tau & 0 \\
0 & \tau
\end{array}\right) \\
& \mathbf{C}_{\mathbf{r}}=\left(\begin{array}{ll}
1 & 0 \\
0 & 1
\end{array}\right), \\
& \mathbf{A}_{\mathbf{i} \tau}=\left(\begin{array}{ccc}
1 & 0 & \frac{\tau a_{3}^{2}}{a_{1}}+\frac{\tau a_{3}}{a_{1} C R_{d c}} \\
0 & 1 & 0 \\
0 & 0 & 1-\tau a_{3}-\frac{\tau}{C R_{d c}}
\end{array}\right) \\
& \mathbf{B}_{\mathbf{i} \tau}=\left(\begin{array}{cc}
\frac{\tau}{a_{1}} & -\frac{\tau a_{2}}{a_{1}} \\
0 & \tau \\
0 & 0
\end{array}\right), \\
& \mathbf{C}_{\mathbf{i}}=\left(\begin{array}{lll}
0 & 0 & 1 \\
0 & 1 & 0
\end{array}\right) .
\end{aligned}
$$

Assume that the pairs $\left(\mathbf{A}_{\mathbf{r} \tau}, \mathbf{B}_{\mathbf{r} \tau}\right),\left(\mathbf{A}_{\mathbf{i} \tau}, \mathbf{B}_{\mathbf{i} \tau}\right)$ are controllable and the pairs $\left(\mathbf{A}_{\mathbf{r} \tau}, \mathbf{C}_{\mathbf{r}}\right),\left(\mathbf{A}_{\mathbf{i} \tau}, \mathbf{C}_{\mathbf{i}}\right)$ are observable through properly sampling output variables.

\section{Discrete Sliding Mode Control of VSC-HVDC System}

In ideal continuous-time case, the SMC (sliding mode control) switches at infinite frequency and forces the states to slide on the so-called switching hyperplane. In practical applications, direct implementation of continuous-time SMC schemes using digital elements, which are considered as the device for imperfect switching, will inevitably induce chattering phenomenon and deteriorate performance or even induce instability. Chattering will cause serious harmonics which is undesirable in VSC-HVDC systems. Hence, the controller design using the discrete-time SMC (DSMC) algorithm is desirable for a successful implementation of the VSC-HVDC control systems. And due to the finite sampling frequency, the controller inputs are calculated once per sampling period and held constant during that interval. Under such a circumstance, the trajectories of the system states of interest are unable to precisely move along the sliding surface, which will lead to a quasi sliding mode motion only [18]. Therefore, only using static output feedback technology has not effectively ensured the control effect of discrete sliding mode control. The fast output sampling technology should be used $[17,19]$.

3.1. Fast Output Sampling (FOS) Technology. Compared with the static output feedback technology, FOS not only keeps its advantage, but also can randomly configure the system poles and always make the closed loop system stable. And then FOS can ensure the effectiveness of the discrete sliding mode control. In the FOS, every sampling period $\tau$ is divided into $N$ subintervals. Here $\Delta=\tau / N$ and $N$ is equal to or greater than the observable index of system $(\mathbf{A}, \mathbf{B})$. The output variables are measured at time instants $t=l \Delta, l=0,1, \ldots, N-1$. Consider the discrete-time system having be at time $t=k \tau$; the fast output samples are obtained as $[17,19]$

$$
\mathbf{y}_{\mathbf{k}}=\left[\begin{array}{c}
y((k-1) \tau) \\
y((k-1) \tau+\Delta) \\
\vdots \\
y((k-1) \tau+(N-1) \Delta)
\end{array}\right] .
$$

Then the rectifier side can be expressed as

$$
\begin{aligned}
\mathbf{x}_{1,2}(\mathrm{k}) & =\mathrm{A}_{\mathrm{r} \tau} \mathbf{x}_{1,2}(\mathrm{k}-1)+\mathrm{B}_{\mathrm{r} \tau} v_{1,2}(\mathrm{k}-1) \\
\mathrm{y}_{1,2 \mathrm{k}} & =\mathrm{C}_{\mathbf{r} 0} \mathrm{x}_{1,2}(\mathrm{k}-\mathbf{1})+\mathrm{D}_{\mathrm{r} 0} v_{1,2}(\mathrm{k}-1)
\end{aligned}
$$


where

$$
\begin{aligned}
C_{r 0} & =\left[\begin{array}{c}
C_{r} \\
C_{r} A_{r} \\
\vdots \\
C_{r} A_{r}^{N_{1}-1}
\end{array}\right], \\
D_{r 0} & =\left[\begin{array}{c}
0 \\
C_{r} B_{r} \\
\vdots \\
C_{r} \sum_{j=0}^{N_{1}-2} A_{r}^{j} B_{r}
\end{array}\right] .
\end{aligned}
$$

And assume that $\mathbf{C}_{\mathbf{r} 0}$ and $\mathbf{D}_{\mathbf{r} 0}$ are invertible through appropriate choice. $\left(\mathbf{A}_{\mathbf{r}} \quad \mathbf{B}_{\mathbf{r}} \mathbf{C}_{\mathbf{r}}\right)$ is the system parameter matrix with sampling rate $1 / \Delta_{1}, \Delta_{1}=\tau / N_{1}$.

Define $\mathbf{y}_{\mathbf{1}, \mathbf{2 k}}=\left(\begin{array}{l}y_{1}((k-1) \tau) \\ y_{2}((k-1) \tau)\end{array}\right)$. This means $y_{1}$ is sampled once and $y_{2}$ is sampled once in each sampling period $\tau$.

The inverter side can be expressed as

$$
\begin{aligned}
\mathbf{x}_{3,4,5}(k) & =\mathrm{A}_{\mathbf{i} \tau} \mathbf{x}_{3,4,5}(\mathrm{k}-1)+\mathrm{B}_{\mathrm{i} \tau} v_{3,4}(\mathrm{k}-\mathbf{1}) \\
\mathbf{y}_{3,4 \mathrm{k}} & =\mathrm{C}_{\mathbf{i} 0} \mathbf{x}_{3,4,5}(\mathrm{k}-\mathbf{1})+\mathrm{D}_{\mathbf{i} 0} v_{3,4}(\mathrm{k}-\mathbf{1}),
\end{aligned}
$$

where

$$
\begin{aligned}
& \mathrm{C}_{\mathbf{i} 0}=\left[\begin{array}{c}
\mathrm{C}_{\mathbf{i}} \\
\mathrm{C}_{\mathrm{i}} \mathrm{A}_{\mathrm{i}} \\
\vdots \\
\mathrm{C}_{\mathbf{i}} \mathrm{A}_{\mathrm{i}}^{\mathrm{N}_{2}-1}
\end{array}\right] \text {, } \\
& D_{i 0}=\left[\begin{array}{c}
0 \\
C_{i} B_{i} \\
\vdots \\
C_{i} \sum_{j=0}^{N_{2}-2} A_{i}^{j} B_{i}
\end{array}\right] \text {. }
\end{aligned}
$$

And assume that $\mathbf{C}_{\mathbf{i} 0}$ and $\mathbf{D}_{\mathbf{i} 0}$ are invertible through appropriate choice. $\left(\mathbf{A}_{\mathbf{i}} \quad \mathbf{B}_{\mathbf{i}} \quad \mathbf{C}_{\mathbf{i}}\right)$ is the system parameter matrix with sampling rate $1 / \Delta_{2}, \Delta_{2}=\tau / N_{2}$.

Define $\mathbf{y}_{\mathbf{3}, \mathbf{4} \mathbf{k}}=\left(\begin{array}{c}y_{3}((k-1) \tau) \\ y_{3}\left((k-1) \tau+\Delta_{2}\right) \\ y_{4}((k-1) \tau)\end{array}\right)$. This means $y_{3}$ is sampled twice and $y_{4}$ is sampled once in each sampling period $\tau$.

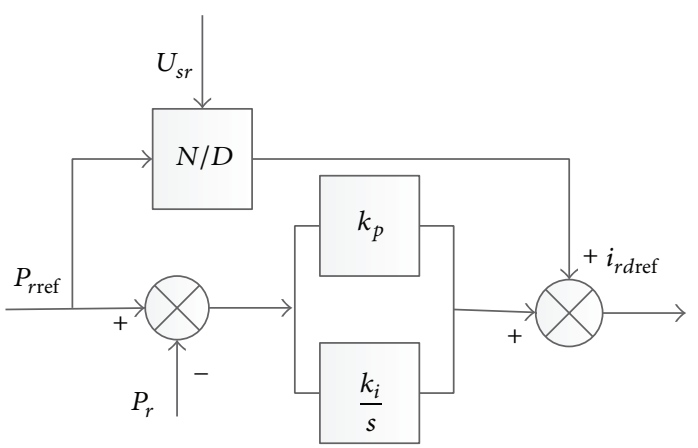

(a) The reference value of $d$ axis current

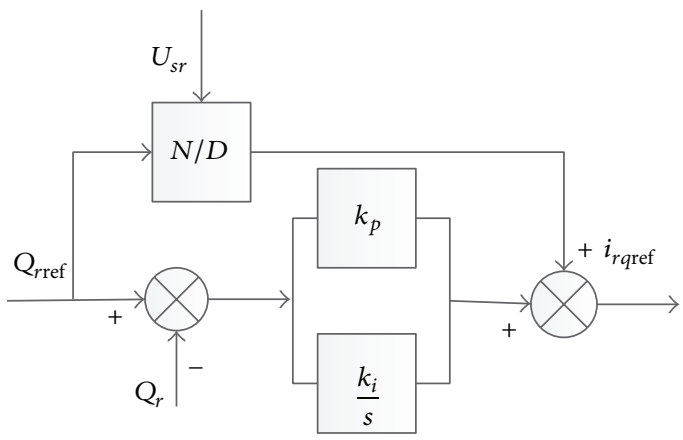

(b) The reference value of $q$ axis current

FIGURE 2: Control block diagrams of output references value at the rectifier station.

According to (20) and (22), state vectors $x_{1,2}(k)$ and $x_{3,4,5}(k)$ can be deduced as

$$
\begin{aligned}
\mathbf{x}_{1,2}(\mathrm{k})= & \mathrm{A}_{\mathrm{r} \tau} \mathrm{C}_{\mathrm{r} 0}{ }^{-1} \mathrm{y}_{1,2 \mathrm{k}} \\
& +\left(\mathrm{B}_{\mathrm{r} \tau}-\mathrm{A}_{\mathrm{r} \tau} \mathrm{C}_{\mathrm{r} 0}{ }^{-1} \mathrm{D}_{\mathrm{r} 0}\right) v_{1,2}(\mathrm{k}-1), \\
\mathbf{x}_{3,4,5}(\mathrm{k})= & \mathrm{A}_{\mathrm{i} \tau} \mathrm{C}_{\mathbf{i} 0}{ }^{-1} \mathbf{y}_{3,4 k} \\
& +\left(\mathrm{B}_{\mathrm{i} \tau}-\mathrm{A}_{\mathrm{i} \tau} \mathrm{C}_{\mathrm{i} 0}{ }^{-1} \mathrm{D}_{\mathrm{i} 0}\right) v_{3,4}(\mathrm{k}-1) .
\end{aligned}
$$

3.2. The Rectifier Side Control. The differences between output and reference variables are denoted by (26). Because the relative degrees of $y_{1}$ and $y_{2}$ are, respectively, equal to 1,1 , the sliding mode surfaces are defined as (27). Consider

$$
\mathbf{e}_{\mathbf{1 , 2}}=\left(\begin{array}{c}
e_{1} \\
e_{2}
\end{array}\right)=\left(\begin{array}{c}
y_{1}(k)-i_{r d \text { ref }}(k) \\
y_{2}(k)-i_{r q \text { ref }}(k)
\end{array}\right),
$$

where $i_{r d \text { ref }}(k)$ and $i_{r q \text { ref }}(k)$ are the reference values. Their calculation processes are shown in Figure 2. $P_{r}, P_{r \text { ref }}, Q_{r}$, and $Q_{\text {rref }}$ are, respectively, the output value and reference value of active and reactive power. Consider

$$
\mathbf{s}_{\mathbf{1 , 2}}=\left(\begin{array}{l}
s_{1} \\
s_{2}
\end{array}\right)=\left(\begin{array}{l}
e_{1}(k) \\
e_{2}(k)
\end{array}\right) \text {. }
$$




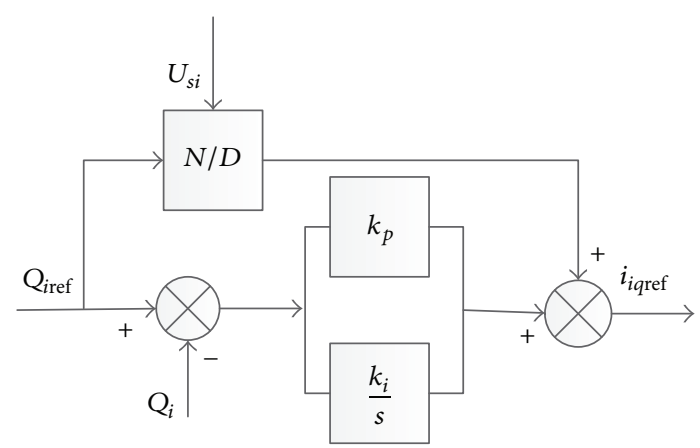

FIGURE 3: Control block diagram of output reference value at the inverter station.

Desired state trajectories of the discrete variable structure system shown as in (28) can be obtained by control law based on reaching law method:

$$
\begin{aligned}
& s_{1}(k+1)-s_{1}(k)=-\rho_{1} \tau s_{1}(k)-\varepsilon_{1} \tau \operatorname{sgn}\left(s_{1}(k)\right), \\
& s_{2}(k+1)-s_{2}(k)=-\rho_{2} \tau s_{2}(k)-\varepsilon_{2} \tau \operatorname{sgn}\left(s_{2}(k)\right),
\end{aligned}
$$

where $\rho_{1}, \rho_{2}, \varepsilon_{1}$, and $\varepsilon_{2}$ are all greater than zero. And $1-\rho_{1} \tau>$ $0,1-\rho_{2} \tau>0$.

Now replacing (26) with (27) and then with (28), the virtual control variables can be denoted by

$$
\begin{aligned}
& v_{1}(k)=-\rho_{1} s_{1}(k)-\varepsilon_{1} \operatorname{sgn}\left(s_{1}(k)\right), \\
& v_{2}(k)=-\rho_{2} s_{2}(k)-\varepsilon_{2} \operatorname{sgn}\left(s_{2}(k)\right) .
\end{aligned}
$$

The control variables shown as in (30) can be deduced by (14), (24), and (29):

$$
\begin{aligned}
& u_{1}(k)=-R_{r} Q_{r 1}+\omega L_{r} Q_{r 2}-L_{r} v_{1}+U_{s r d}, \\
& u_{2}(k)=-\omega L_{r} Q_{r 1}-R_{r} Q_{r 2}-L_{r} v_{2}+U_{s r q},
\end{aligned}
$$

where $Q_{r 1}$ and $Q_{r 2}$ are the first and second row of $\mathbf{x}_{1,2}(\mathbf{k})$ in Section 3.1. $u_{1}(k), u_{2}(k)$ can be expressed by $\mathbf{y}_{1,2}(\mathbf{k})$ through FOS.

3.3. The Inverter Side Control. The differences between output and reference variables are denoted by (31). Because the relative degrees of $y_{3}$ and $y_{4}$ are, respectively, equal to 2,1 , the sliding mode surfaces are defined as (32). Consider

$$
\mathbf{e}_{3,4}=\left(\begin{array}{c}
e_{3} \\
e_{4}
\end{array}\right)=\left(\begin{array}{c}
y_{3}(k)-U_{d c r e f}(k) \\
y_{4}(k)-i_{\text {iqref }}(k)
\end{array}\right)
$$

where $U_{d c \text { ref }}(k)$ and $i_{i q r e f}(k)$ are the reference values. Usually $U_{d c r e f}(k)$ is known. The calculation process of $i_{i q r e f}(k)$ is shown in Figure 3. $Q_{i}$ and $Q_{i \text { iref }}$ are, respectively, the output and reference value of reactive power:

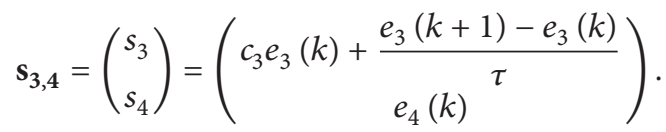

Similar to the rectifier side, desired state trajectories of the discrete variable structure system shown as in (33) can be obtained by control law based on reaching law method:

$$
\begin{aligned}
& s_{3}(k+1)-s_{3}(k)=-\rho_{3} \tau s_{3}(k)-\varepsilon_{3} \tau \operatorname{sgn}\left(s_{3}(k)\right), \\
& s_{4}(k+1)-s_{4}(k)=-\rho_{4} \tau s_{4}(k)-\varepsilon_{4} \tau \operatorname{sgn}\left(s_{4}(k)\right),
\end{aligned}
$$

where $\rho_{3}, \rho_{4}, \varepsilon_{3}$, and $\varepsilon_{4}$ are all greater than zero. And $1-\rho_{3} \tau>$ $0,1-\rho_{4} \tau>0$.

Now replacing (31) with (32) and then with (33), the virtual control variables can be denoted by

$$
\begin{aligned}
v_{3}(k)= & -\rho_{3} s_{3}(k)-\varepsilon_{3} \operatorname{sgn}\left(s_{3}(k)\right) \\
& -\frac{c_{3}\left[y_{3}(k+1)-y_{3}(k)\right]}{\tau}, \\
v_{4}(k)= & -\rho_{4} s_{4}(k)-\varepsilon_{4} \operatorname{sgn}\left(s_{4}(k)\right) .
\end{aligned}
$$

The control variables shown as in (35) can be deduced by (15), (25), and (34):

$$
\begin{aligned}
u_{3}(k)= & -R_{i} Q_{i 3}+\omega_{i} L_{i} Q_{i 4}-\frac{L_{i} a_{3}}{a_{1}}\left(a_{3}+\frac{2}{C R_{d c}}\right) Q_{i 5} \\
& -\frac{L_{i}}{a_{1}} v_{3}+\frac{L_{i} a_{2}}{a_{1}} v_{4}+\frac{L_{i} a_{3} U_{d c 1}}{a_{1} C R_{d c}}+U_{s i d}, \\
u_{4}(k)= & -\omega_{i} L_{i} Q_{i 3}-R_{i} Q_{i 4}-L_{i} v_{4}+U_{s i q},
\end{aligned}
$$

where $Q_{i 3}, Q_{i 4}$, and $Q_{i 5}$ are the first, second, and third row of $\mathbf{x}_{3,4,5}(\mathbf{k})$ in Section 3.1. $u_{3}(k)$ and $u_{4}(k)$ can be expressed by $\mathbf{y}_{\mathbf{3}, \mathbf{4}}(\mathbf{k})$ through FOS.

\section{Simulation Results}

The typical VSC-HVDC system composed of two converter stations is taken as example and the detailed parameters are shown in Table 1. The simulation experiment is performed in MATLAB/SIMULINK. In the per-unit value system, the based power is $200 \mathrm{MW}$, the based voltage at AC side is $81.65 \mathrm{KV}$, and the based voltage at DC side is $100 \mathrm{KV}$. The sampling period $\tau=74 \mu \mathrm{s}$. Also $N_{1}=1$ and $N_{2}=2$. The discrete SMC controllers parameters are $\rho_{1}=\rho_{2}=1100$, $\varepsilon_{1}=\varepsilon_{2}=3, \rho_{3}=\rho_{4}=1000, \varepsilon_{3}=\varepsilon_{4}=3$, and $c_{3}=1200$.

4.1. The Steady State Operation. In steady state operation, $P_{\text {rref }}, U_{d c r e f}, Q_{i r e f}$, and $Q_{i r e f}$ are, respectively, $1 \mathrm{pu}, 0 \mathrm{pu}, 1 \mathrm{pu}$, and $0 \mathrm{pu}$. As shown in Figure 4, the active, reactive power and DC voltage can track their reference values effectively. The proposed mathematical model and control strategy can be proved to make the system operate well in steady state condition. 


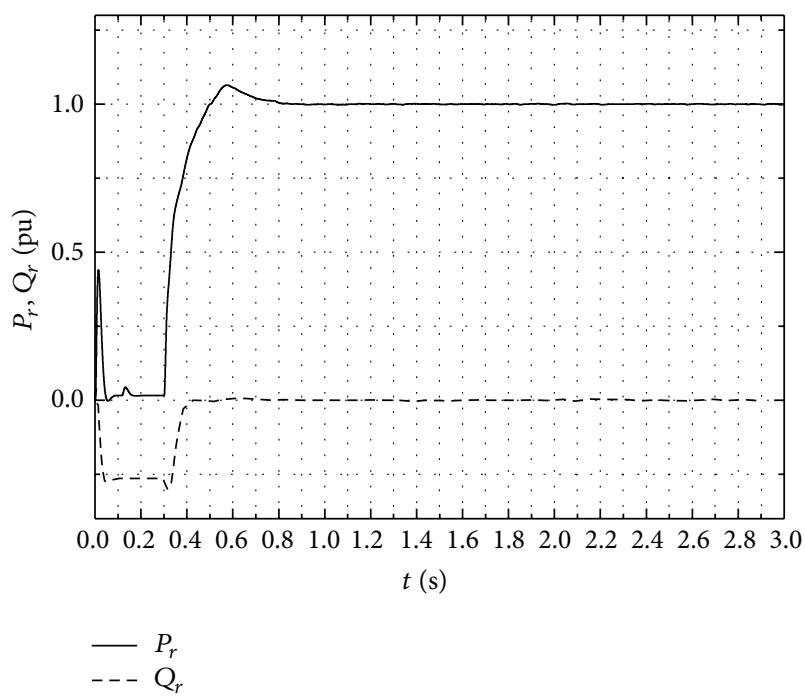

(a) The active and reactive power at rectifier side

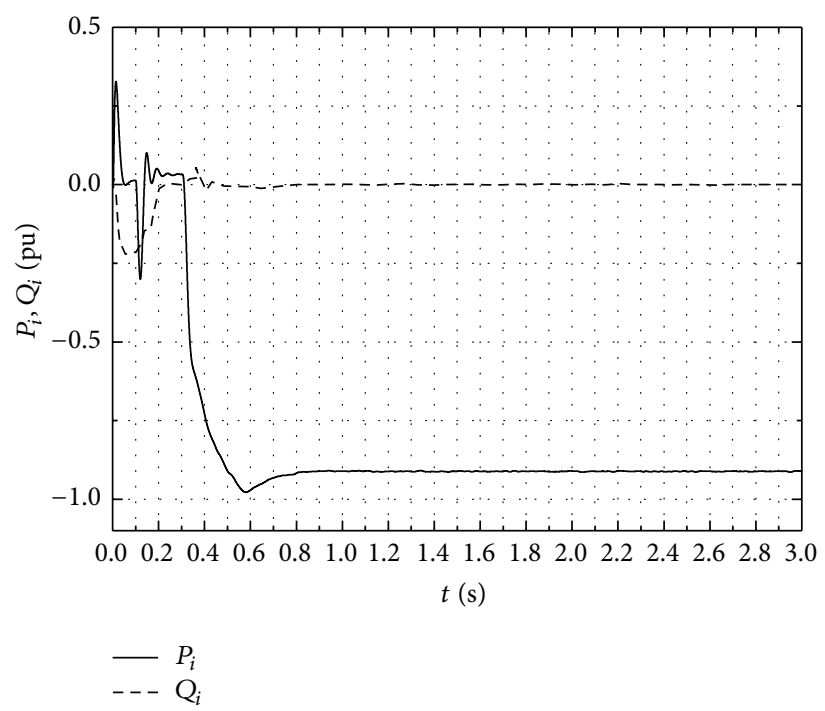

(b) The active and reactive power at inverter side

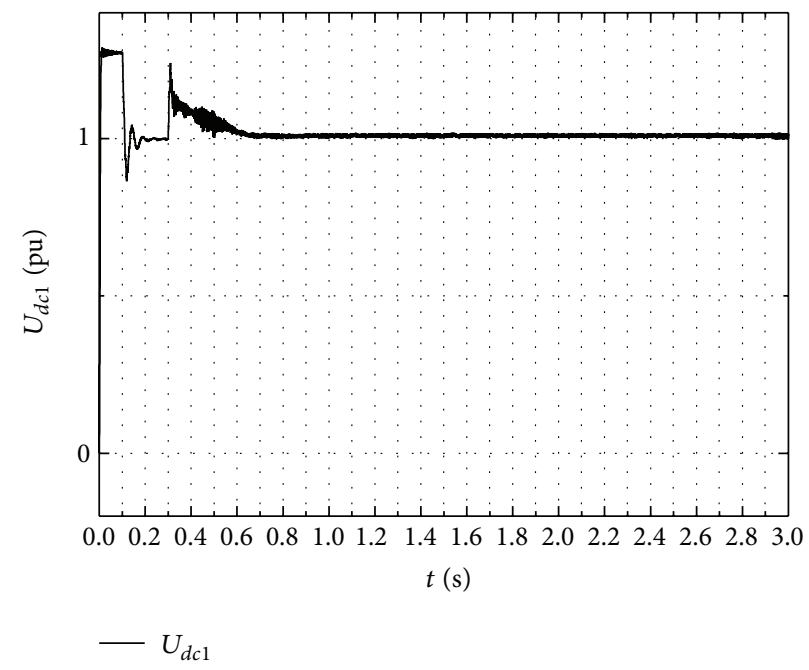

(c) The DC voltage

FIGURE 4: Responses of the rectifier and inverter in steady state operation.

TABLE 1: The system parameters of three-level VSC-HVDC.

\begin{tabular}{lc}
\hline Parameters & Value \\
\hline AC voltages $U_{s r}, U_{s i}$ & $230 \mathrm{kv}$ \\
$\omega_{r}, \omega_{i}$ & $2 * \mathrm{pi} * 50 \mathrm{rad} / \mathrm{s}$ \\
Transformer ratio $T_{1}, T_{2}$ & $230 \mathrm{kv} / 100 \mathrm{kv}$ \\
$R_{r}, R_{i}$ & $0.325 \Omega$ \\
$L_{r}, L_{i}$ & $0.072 \mathrm{H}$ \\
Rated voltage in DC side & $\pm 100 \mathrm{kv}$ \\
$C$ & $70 \mu \mathrm{F}$ \\
Unit resistance of DC line & $1.39 e-002 \Omega / \mathrm{km}$ \\
DC line length & $75 * 2 \mathrm{~km}$ \\
Switching frequency & $1350 \mathrm{HZ}$ \\
\hline
\end{tabular}

4.2. Reversion and Step Changes. As shown in Figure 5, the change process of $P_{\text {rref }}$ is as follows: the $P_{\text {rref }}$ keeps 1 pu from
$0 \mathrm{~s}$ to $1.5 \mathrm{~s}$. At $1.5 \mathrm{~s}$, it steps to $-1 \mathrm{pu}$, and then keeps this value until $3.0 \mathrm{~s}$. At last, it steps to $1 \mathrm{pu}$ at $3.0 \mathrm{~s}$. From the experimental results, the referred changes least affect the reactive power on the rectifier side and reactive power on the inverter side. As shown in Figure 6, the change process of $Q_{r \text { ref }}$ is as follows: the $Q_{r \text { ref }}$ keeps 0 pu from 0 s to $1.5 \mathrm{~s}$. And then steps to $0.1 \mathrm{pu}$ at $1.5 \mathrm{~s}$. The change process of $Q_{i \mathrm{ref}}$ is as follows: the $Q_{i \text { ref }}$ keeps 0 pu from 0 s to $2.5 \mathrm{~s}$. And then steps to $-0.1 \mathrm{pu}$ at $2.5 \mathrm{~s}$. From the experimental results, the referred changes least affect the active power on the rectifier side and the active power on the inverter side. These can prove that the proposed discrete SMC strategy can make the active and reactive power decoupled and independent.

4.3. Robustness Test. The equivalent resistance and inductance at the converter stations both reduce $20 \%$. The experimental results are shown in Figure 7. The reference values 


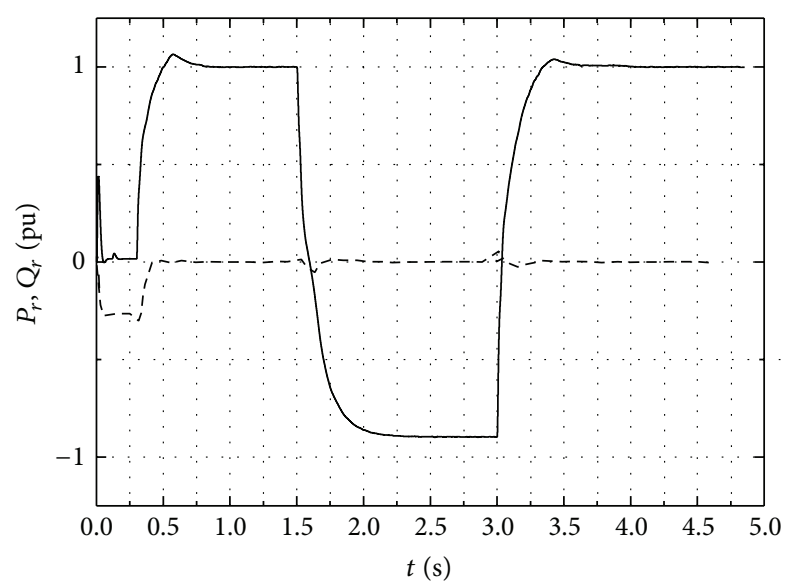

$-P_{r}$
$--Q_{r}$

(a) The active and reactive power at rectifier side

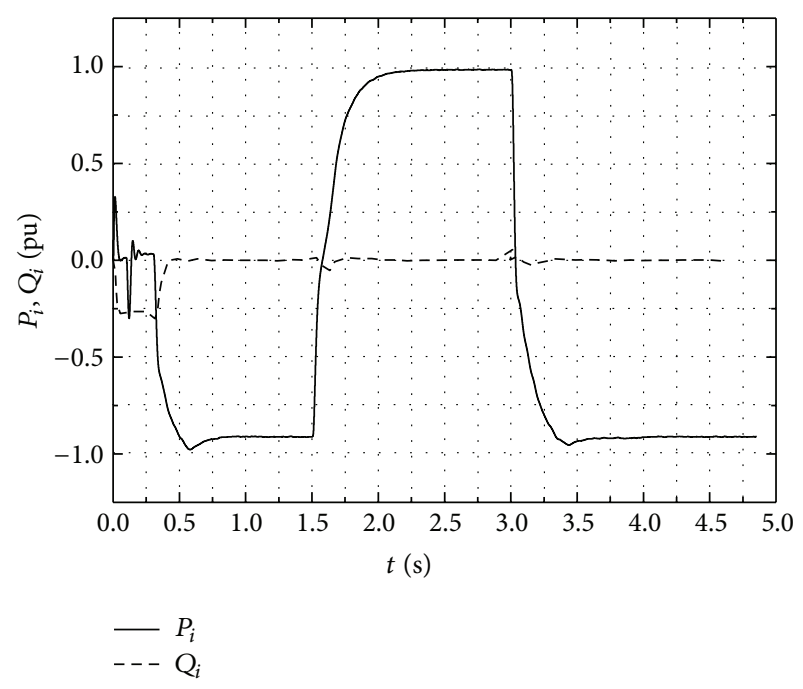

(b) The active and reactive power at inverter side

FIGURE 5: Responses of the rectifier and inverter when active power reverses.

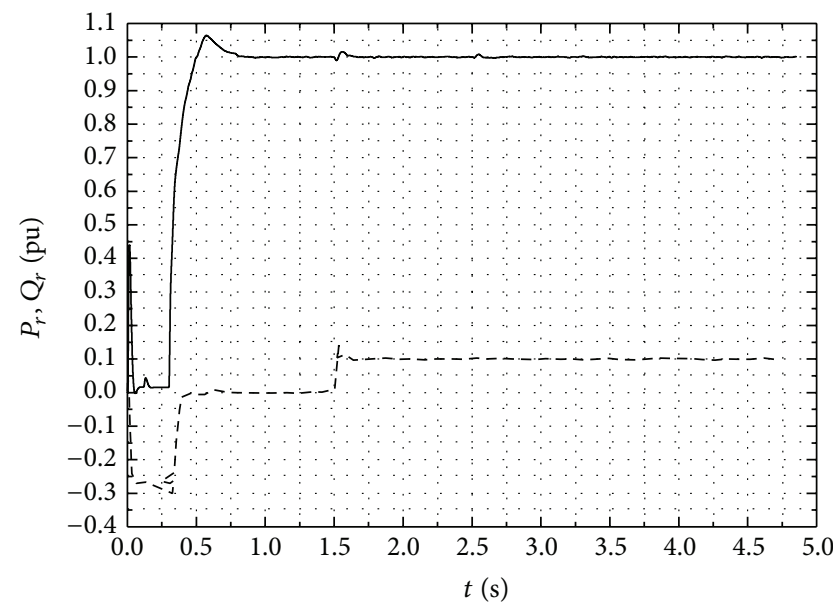

$-P_{r}$

(a) The active and reactive power at rectifier side

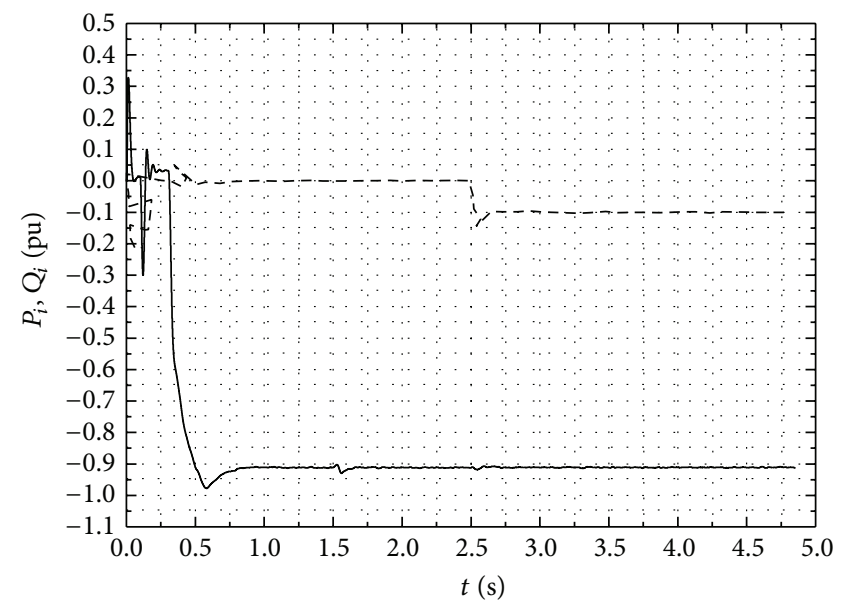

$-P_{i}$

(b) The active and reactive power at inverter side

FIGURE 6: Responses of the rectifier and inverter when the reactive power step changes.

are the same as those in Section 4.1. The active, reactive power and DC voltage can track their reference values smoothly and quickly. This can prove that the proposed control strategy has good robustness.

\section{Conclusions}

This paper deduces the discrete mathematical model of VSCHVDC system by nonlinear input-output feedback linearization method. Based on this, the discrete sliding mode robust controllers are designed. And to ensure the effectiveness of the controllers in quasi sliding mode condition, the FOS technology is used in output feedback. The results from simulation experiment in MATLAB/SIMULINK prove the effectiveness of proposed discrete mathematical model and control strategy. Since the actual computer control system is discrete sampling and SMC has a promising prospect, the proposed discrete mathematical model and control strategy have certain practical application prospect.

\section{Conflict of Interests}

The authors declare that there is no conflict of interests regarding the publication of this paper. 


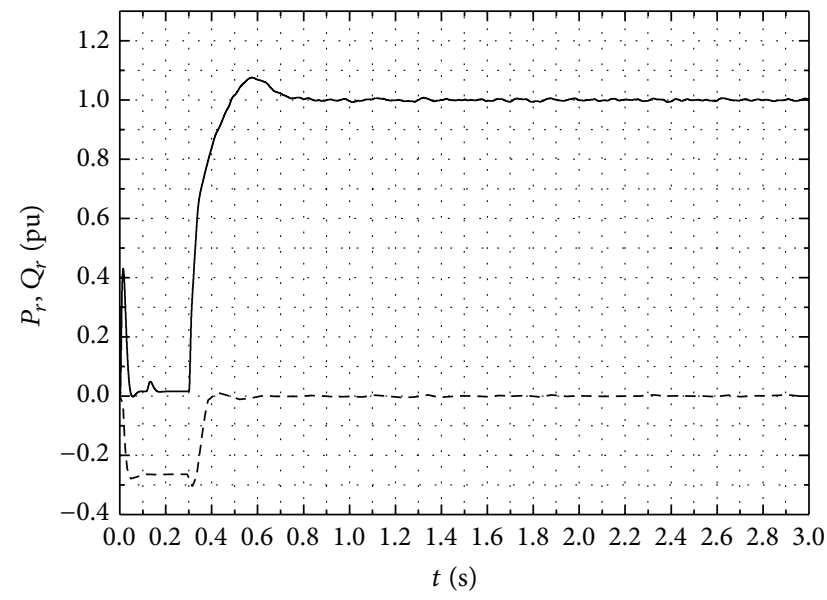

$-P_{r}$

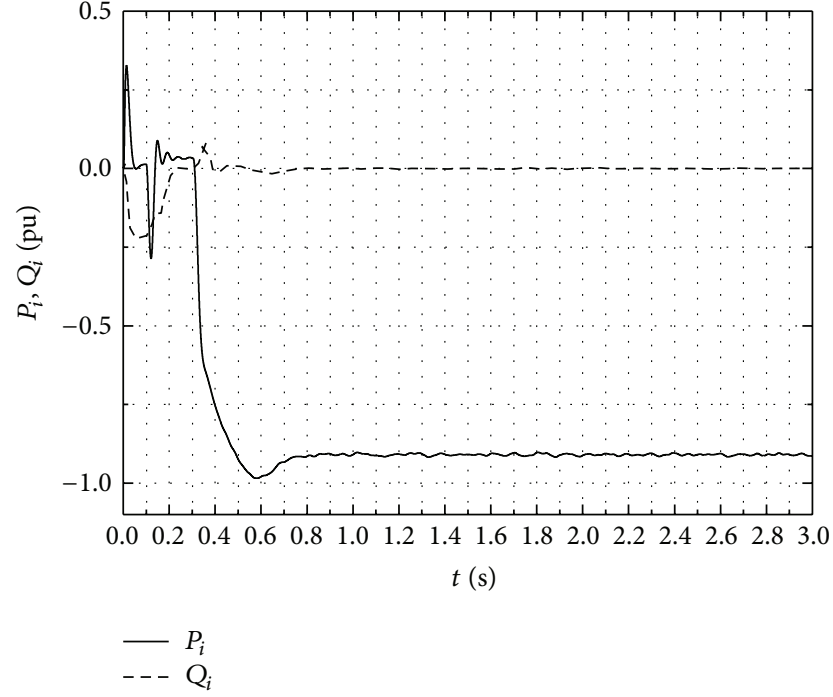

(b) The active and reactive power at inverter side

(a) The active and reactive power at rectifier side

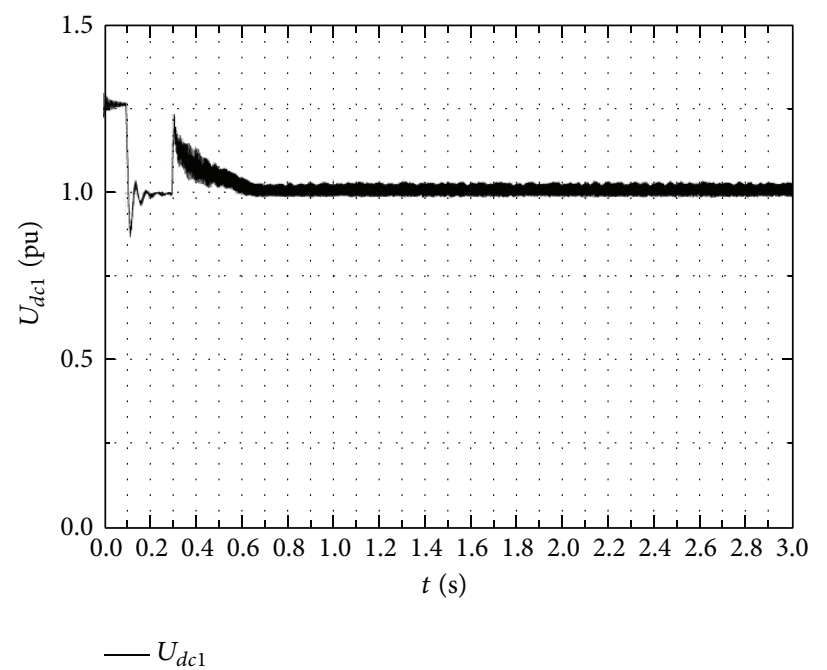

(c) The DC voltage

FIGURE 7: Responses of the rectifier and inverter when the inner parameters change at both converter stations.

\section{Acknowledgment}

This work is supported by the Natural Science Foundation of China (51377068).

\section{References}

[1] N. Flourentzou, V. G. Agelidis, and G. D. Demetriades, "VSCbased HVDC power transmission systems: an overview," IEEE Transactions on Power Electronics, vol. 24, no. 3, pp. 592-602, 2009.

[2] Y. Wei, Q. He, Y. Sun, and C. Ji, "Improved power flow algorithm for VSC-HVDC system based on high-order newtontype method," Mathematical Problems in Engineering, vol. 2013, Article ID 235316, 10 pages, 2013.

[3] L. Zhang, L. Harnefors, and H.-P. Nee, "Interconnection of two very weak AC systems by VSC-HVDC links using power-synchronization control," IEEE Transactions on Power Systems, vol. 26, no. 1, pp. 344-355, 2011.

[4] L. Zhang, L. Harnefors, and H.-P. Nee, "Modeling and control of VSC-HVDC links connected to island systems," IEEE Transactions on Power Systems, vol. 26, no. 2, pp. 783-793, 2011.

[5] F. Xu and Z. Xu, "A modular multilevel power flow controller for meshed HVDC grids," Science China Technological Sciences, vol. 57, no. 9, pp. 1773-1784, 2014.

[6] G. Zhang and Z. Xu, "Steady-state model for VSC based HVDC and its controller design," in Proceedings of the IEEE Power Engineering Society Winter Meeting, vol. 3, pp. 1085-1090, February 2001.

[7] M. Yin, G.-Y. Li, T.-Y. Niu, G.-K. Li, H.-F. Liang, and M. Zhou, "Continuous-time state-space model of VSC-HVDC and its control strategy," Proceedings of the Chinese Society of Electrical Engineering, vol. 25, no. 18, pp. 34-39, 2005.

[8] R. Song, C. Zheng, R. Li, and Z. Xiaoxin, "VSCs based HVDC and its control strategy," in Proceedings of the IEEE/PES 
Transmission and Distribution Conference and Exhibition: Asia and Pacific, pp. 1-6, August 2005.

[9] S.-Y. Ruan, G.-J. Li, X.-H. Jiao, Y.-Z. Sun, and T. T. Lie, "Adaptive control design for VSC-HVDC systems based on backstepping method," Electric Power Systems Research, vol. 77, no. 5-6, pp. 559-565, 2007.

[10] A. Moharana and P. K. Dash, "Input-output linearization and robust sliding-mode controller for the VSC-HVDC transmission link," IEEE Transactions on Power Delivery, vol. 25, no. 3, pp. 1952-1961, 2010.

[11] N. Nayak, S. K. Routray, and P. K. Rout, "State feedback robust $H_{\infty}$ controller for transient stability enhancement of Vsc-Hvdc transmission systems," Procedia Technology, vol. 4, pp. 652-660, 2012, Proceedings of the 2nd International Conference on Computer, Communication, Control and Information Technology (C3IT '12) on February 25-26, 2012.

[12] H. S. Ramadan, H. Siguerdidjane, M. Petit, and R. Kaczmarek, "Performance enhancement and robustness assessment of VSC-HVDC transmission systems controllers under uncertainties," International Journal of Electrical Power \& Energy Systems, vol. 35, no. 1, pp. 34-46, 2012.

[13] X.-G. Wei, G.-F. Tang, and J.-C. Zheng, "Study of VSC-HVDC discrete model and its control strategies," Proceedings of the Chinese Society of Electrical Engineering, vol. 27, no. 28, pp. 6-11, 2007.

[14] H. Yang, N. Zhang, and M. J. Ye, "Study of VSC-HVDC connected to passive network discrete model and its control strategies," Power System Protection and Control, vol. 40, no. 4, pp. 37-42, 2012.

[15] V. I. Utkin and H.-C. Chang, "Sliding mode control on electromechanical systems," Mathematical Problems in Engineering, vol. 8, no. 4-5, pp. 451-473, 2002.

[16] H. K. Khalil and J. W. Grizzle, Nonlinear Systems, Prentice hall, Upper Saddle River, NJ, USA, 1996.

[17] H. Werner, "Multimodel robust control by fast output sampling-an lmi approach," Automatica, vol. 34, no. 12, pp. 1625-1630, 1998.

[18] T.-L. Tai and J.-S. Chen, "UPS inverter design using discretetime sliding-mode control scheme," IEEE Transactions on Industrial Electronics, vol. 49, no. 1, pp. 67-75, 2002.

[19] M. C. Saaj, B. Bandyopadhyay, and H. Unbehauen, "A new algorithm for discrete-time sliding-mode control using fast output sampling feedback," IEEE Transactions on Industrial Electronics, vol. 49, no. 3, pp. 518-523, 2002. 


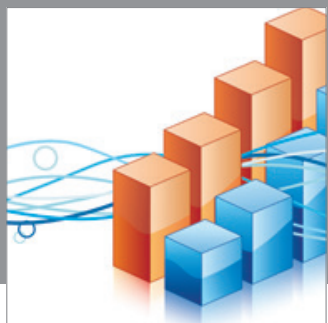

Advances in

Operations Research

mansans

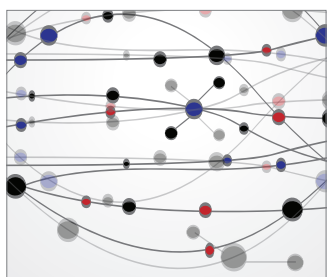

The Scientific World Journal
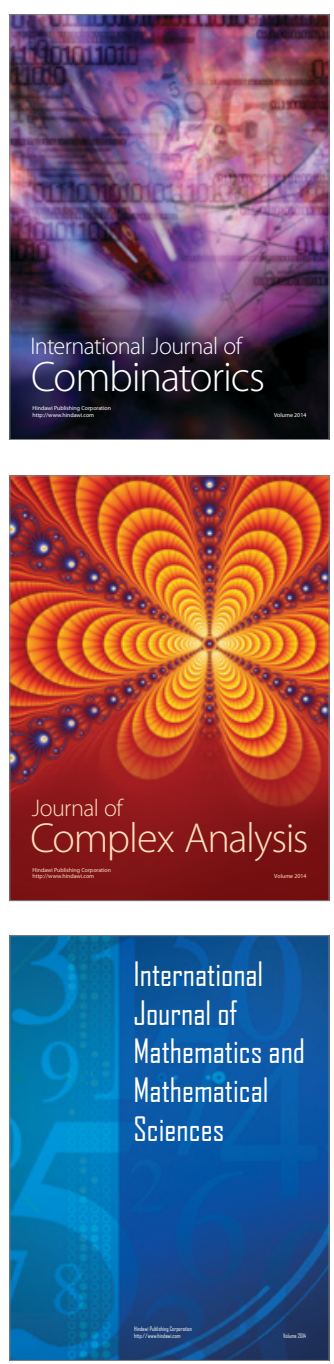
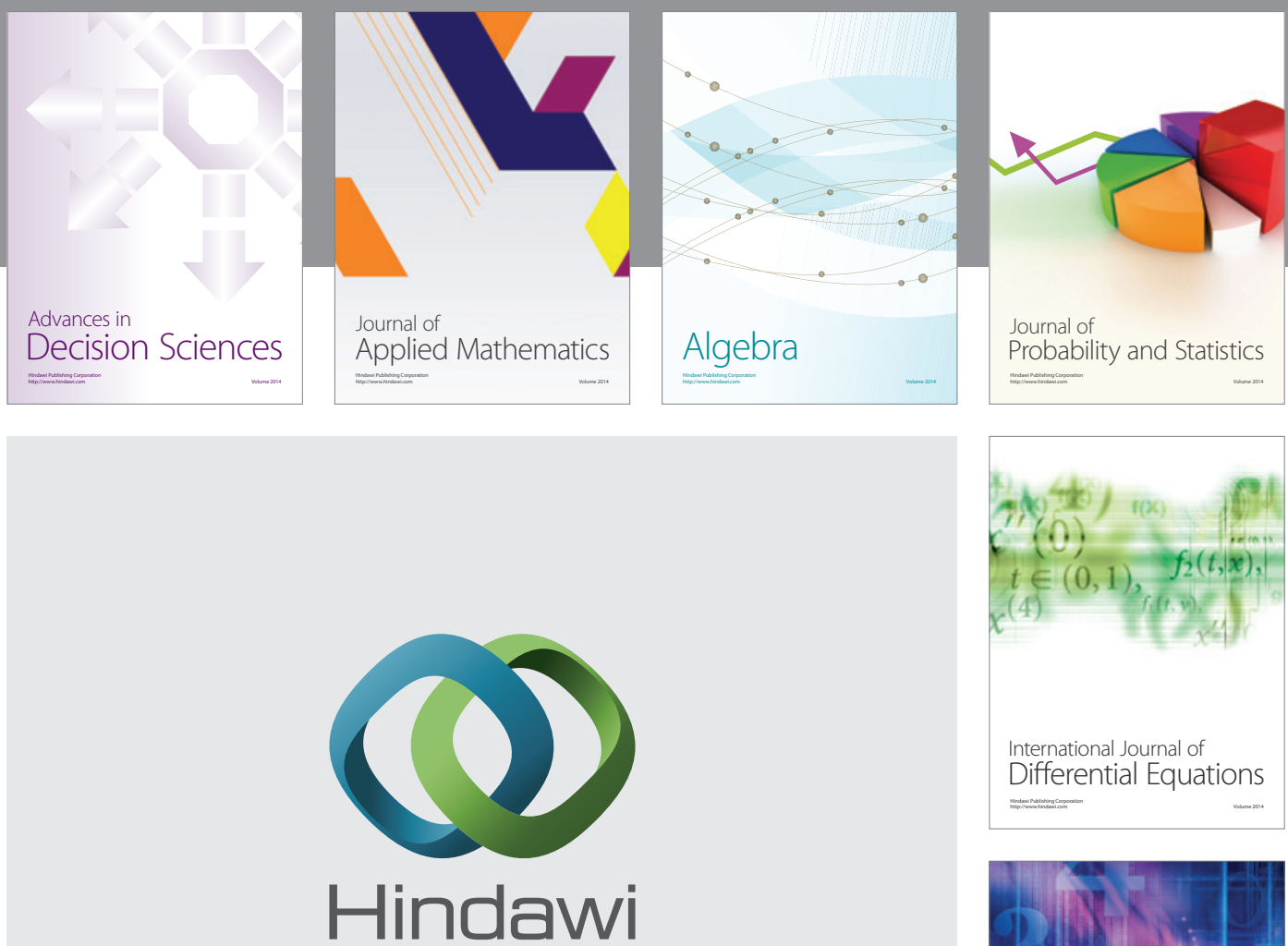

Submit your manuscripts at http://www.hindawi.com
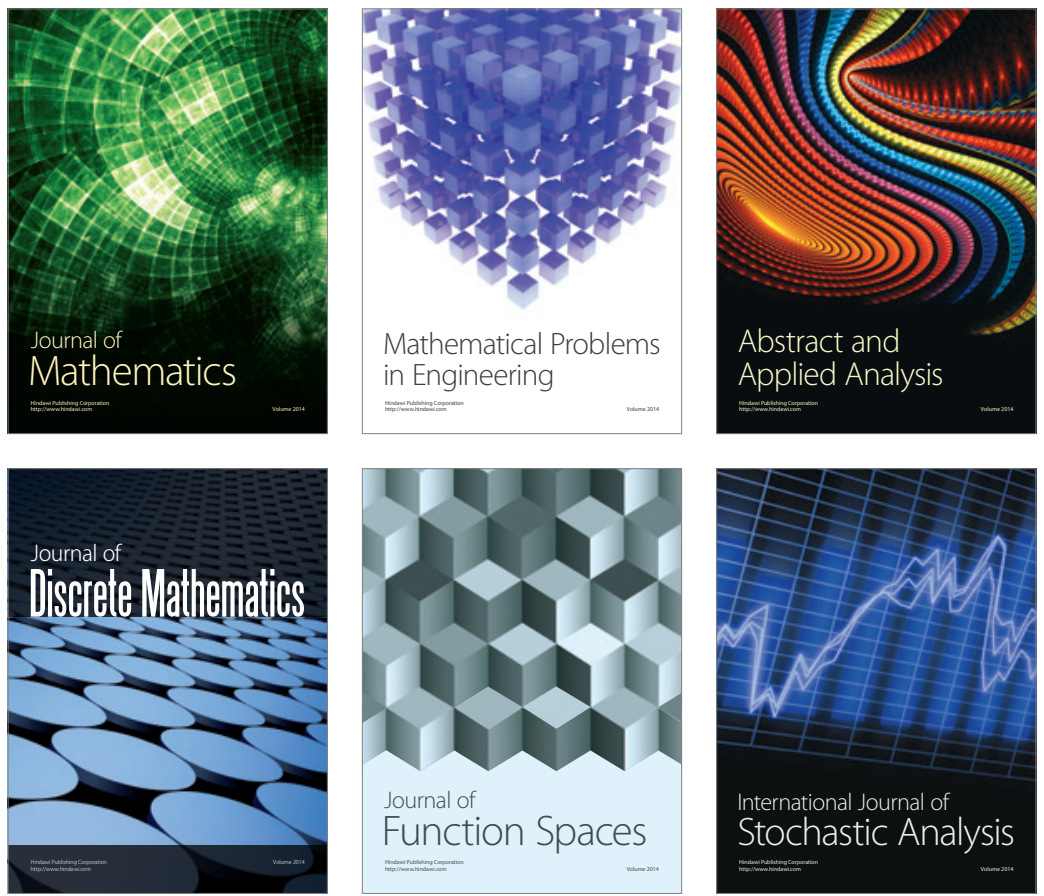

Journal of

Function Spaces

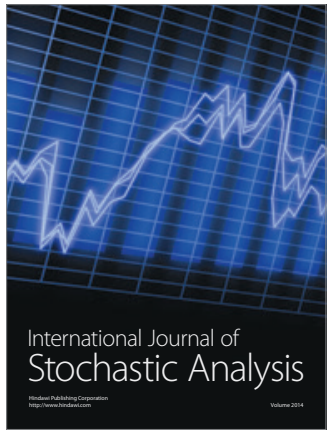

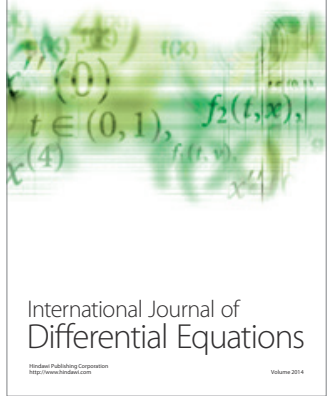
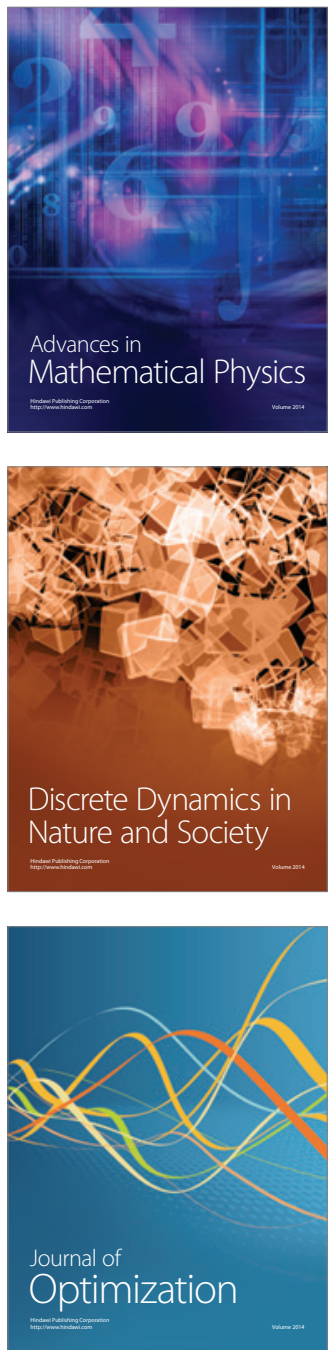